\title{
Síntese de zeólita do tipo faujasita a partir de um rejeito de caulim
}

\author{
(Synthesis of faujasite-type zeolite from kaolin waste)
}

\author{
E. A. Hildebrando , R. S. Angélica ${ }^{2}, R . F$. Neves ${ }^{2}$, F. R. Valenzuela-Diaz ${ }^{I}$ \\ ${ }^{l}$ Laboratório de Matérias-Primas Particuladas e Sólidos não Metálicos, Departamento de Engenharia \\ Metalúrgica e de Materiais, Escola Politécnica da Universidade de S. Paulo, \\ Av. Prof. Mello Moraes 2463, S. Paulo, SP 05508-900 \\ ${ }^{2}$ Universidade Federal do Pará, ITEC/IG, Av. Augusto Corrêa s/n, Belém, PA 66093-110 \\ edemarino@usp.br,angelica@ufpa.br,rfn@ufpa.br,frrvdiaz@usp.br
}

\begin{abstract}
Resumo
Materiais zeolíticos foram sintetizados utilizando como fonte principal de silício e alumínio um rejeito industrial gerado durante o beneficiamento do caulim para cobertura de papel; o material de partida e as fases formadas como produtos de reação foram caracterizados por difração de raios X, microscopia eletrônica de varredura e espectroscopia de refletância difusa no infravermelho com transformada de Fourier. O processo de síntese ocorreu em condições hidrotermais através de autoclavagem estática e os efeitos tempo-temperatura, assim como também as relações $\mathrm{Si} / \mathrm{Al}$ e Na/Al foram considerados. Os resultados mostram que na metodologia desenvolvida com o rejeito de caulim, inicialmente calcinado a $700{ }^{\circ} \mathrm{C}$ por $2 \mathrm{~h}$, submetido em seguida à reação em meio alcalino a $90{ }^{\circ} \mathrm{C}$ por $48 \mathrm{~h}$ na presença de uma fonte adicional de sílica foi obtida zeólita do tipo faujasita com boa cristalinidade como fase predominante no produto de síntese.
\end{abstract}

Palavras-chave: zeólita, faujasita, caulim.

\begin{abstract}
Zeolitic materials were synthesized using as main source of silicon and aluminum an industrial waste generated during the processing of kaolin for paper coating, the starting material and formed phases as reaction products were characterized by XRD, SEM and DRIFT. The synthesis process occurred in hydrothermal conditions and the effects, time-temperature, as well as the relations Si/Al and $\mathrm{Na} / \mathrm{Al}$ were considered. The results show that in the methodology developed from kaolin waste, initially calcined at $700{ }^{\circ} \mathrm{C}$ for $2 \mathrm{~h}$, subjected then reaction in alkaline medium at $90{ }^{\circ} \mathrm{C}$ for $48 \mathrm{~h}$ in presence of additional silica was obtained faujasite-type zeolite with good crystallinity as phase predominant in the synthesis product.
\end{abstract}

Keywords: zeolite, faujasite, kaolin.

\section{INTRODUÇÃO}

As ocorrências de caulim são comuns em diversos países do mundo, porém existem poucos depósitos de boa qualidade e comercialmente exploráveis. Os mais conhecidos estão localizados em três regiões do planeta, encontrando-se eles nos estados da Geórgia e da Carolina do Sul nos Estados Unidos, em Cornwall sudoeste da Inglaterra, e na região Amazônica no Brasil [1]. Dentro do cenário nacional, o estado do Pará se destaca, por possuir um dos mais importantes depósitos de caulim de classe internacional e por ser o principal distrito brasileiro de produção de caulim de alta qualidade para indústria de papel [2]. A mineração e o beneficiamento do caulim, por sua natureza, envolvem atividades que alteram as condições ambientais provocando impactos ao meio físico e biótico [3] fazendo com que este minério, apesar de sua importância em várias indústrias, esteja associado a um grande passivo ambiental [4]. O processo de beneficiamento do caulim destinado para carga e cobertura de papel gera dois tipos de rejeitos: um composto por partículas grosseiras (principalmente quartzo sob a forma de areia), que são repostas no próprio local da lavra, e outro que é armazenado em volumosas lagoas de sedimentação [5]. Pesquisas com esse rejeito demonstram uma grande viabilidade para o mesmo ser utilizado como matériaprima em diversos segmentos industriais $[5,6]$, como por exemplo, na síntese para obtenção de zeólitas [7-9].

Zeólitas, segundo a definição clássica, são aluminosilicatos cristalinos hidratados de metais alcalinos ou alcalinos terrosos, que possuem estrutura aberta, constituídas por tetraedros de sílica $\left[\mathrm{SiO}_{4}\right]^{4-}$ e alumina $\left[\mathrm{AlO}_{4}\right]^{5-}$, ligados entre si por átomos de oxigênio [10]; no entanto atualmente, este conceito pode ser expandido a fim de incluir um grande número de materiais que possuem estruturas semelhantes e que apresentem em sua composição outros cátions 
além do Si e Al, tais como: B, Ge, Fe, P, Co, Zn, etc. A estrutura das zeólitas apresenta rede tridimencional aberta, ordenada em canais de dimensões moleculares formando microporos, podem apresentar ainda em sua organização estrutural um excesso de cargas negativas em virtude da substituição isomórfica de $\mathrm{Si}^{4+}$ por $\mathrm{Al}^{3+}$, estas características proporcionam as zeólitas inúmeras aplicações podendo ser utilizada em processos de adsorção, troca iônica e catálise $[11,12]$. Tradicionalmente as zeólitas são produzidas a partir de hidrogéis de aluminatos e silicatos de sódio, entretanto, a produção de zeólitas a partir de argilas, como fonte de sílica e alumina está sendo continuamente investigada [13]. Pois, a utilização de matérias-primas de baixo custo para sintetizar zeólitas oferece vantagens econômicas sobre padrões químicos sintéticos [14]. Desta forma, diversos grupos de pesquisas têm estudado a preparação de algumas zeólitas a partir de caulins e tem obtido grandes sucessos na síntese principalmente das zeólitas A [15, 16], mordenita [17], zeólita X [18, 19], zeólita Y [20, 21], entre outras.

$\mathrm{O}$ caulim torna-se uma matéria-prima interessante na síntese de materiais zeolíticos em virtude do teor de $\mathrm{SiO}_{2}$ e $\mathrm{Al}_{2} \mathrm{O}_{3}$ serem bastante semelhantes entre si; a chave para um bom rendimento do processo esta em como ativar o caulim para em seguida submetê-lo a síntese hidrotermal, pois as folhas tetraédricas e octaédricas de Si-O e Al-O são praticamente insensíveis a modificações sob moderadas condições [20]. Na ativação térmica do caulim através da calcinação ocorre a remoção de grupos estruturais $\mathrm{OH}$ da caulinita transformando-a em metacaulinita; na fase metacaulinita a folha tetraédrica de átomos de silício persiste, porém de forma distorcida; já a folha octraédrica de átomos de alumínio é fortemente alterada, isto porque, durante esta etapa os átomos de alumínio hexacoordenado passam para uma formação de penta e tetracoordenação aumentando desta forma a reatividade do metacaulim, sendo esta máxima quando o teor de alumínio hexacoordenado for mínimo [22, 23]. Esta transformação do caulim para metacaulim deixa o silício e o alumínio mais livres, fazendo desta forma com que a fase metacaulinita, de natureza amorfa, apresente-se altamente reativa, tornando-se assim mais adequada para a síntese de zeólitas $[18,24]$. O produto zeolítico mais comum preparado a partir de caulim ou metacaulim é a zeolita A (relação Si/Al igual a 1); outros tipos de zeólitas com maior relação $\mathrm{Si} / \mathrm{Al}$, como mordenita e zeólita $\mathrm{X}$ e Y, também podem ser obtidas, para isto, deve-se adicionar ao material de partida, uma fonte adicional de sílica, ou então, através de métodos de lixiviação, procura-se retirar certa quantidade do alumínio que compõe a estrutura da caulinita [19,21].

As zeólitas X e Y, apesar do nome diferente, apresentam a mesma estrutura cristalina, ambas são do tipo faujasita (FAU), suas diferenças residem na relação $\mathrm{Si} / \mathrm{Al}$ intrareticular; quando esta relação se encontra na faixa de 1 a 1,5 é designada como zeólita $X$, e da mesma forma para valores mais altos como zeólita Y [12]. Zeólitas com estrutura do tipo FAU tem sido extensivamente estudada devido as suas aplicações em escala industrial no craqueamento de diversos hidrocarbonetos [25]. São utilizadas em mais de $95 \%$ dos casos no mercado de catálise; possuem um custo bastante elevado e as refinarias de petróleo consomem uma grande quantidade deste tipo de material para a fabricação da gasolina a partir de óleo cru nos processos de craqueamento catalítico em leito fluidizado [26]. São conhecidas por possuírem alta estabilidade térmica, grande diâmetro de poros com uma estrutura rígida e por apresentarem elevado teor de sódio [10]. Portanto, a aplicação do rejeito de caulim, dentro de uma metodologia voltada para a produção de zeólitas pode ser uma boa alternativa para se utilizar este tipo de material no futuro; criando-se assim, uma maneira sustentável e ambientalmente amigável de utilização deste rejeito, gerando desta forma um produto de mais alto valor comercial para ser utilizado industrialmente principalmente em processos de adsorção e catálise.

Neste trabalho sintetizou-se zeólita do tipo faujasita em condições hidrotermais a partir de um rejeito caulinitico proveniente do processo de beneficiamento de caulim extraído na Amazônia, levando-se em consideração os efeitos tempo e temperatura de cristalização, assim como também a relação silício/alumínio, e sódio/alumínio na composição molar da mistura reacional.

\section{MATERIAIS E MÉTODOS}

Foi utilizado como fonte predominante de silício e alumínio, um rejeito de caulim proveniente de uma indústria, localizada no estado do Pará, que realiza o beneficiamento de caulim para cobertura de papel; como fonte secundária de silício foi usado metassilicato de sódio pentahidratado (Casa da Química Ind. e Com. Ltda.). A fonte de metal alcalino adicionada ao processo foi o hidróxido de sódio 6 M (Haloquímica Ind. e Com. Ltda).

Para o processo de zeolitização utilizou-se rejeito de caulim previamente calcinado em forno mufla a $700{ }^{\circ} \mathrm{C}$ por $2 \mathrm{~h}$. As amostras foram baseadas na seguinte composição molar: $x \mathrm{Na}_{2} \mathrm{O}-\mathrm{Al}_{2} \mathrm{O}_{3}-y \mathrm{SiO}_{2}-\mathrm{H}_{2} \mathrm{O}$, adotando-se valores para $x$ na faixa de 1 a $10 \mathrm{~mol}, y$ de 3 a 6 mol, procurando-se manter o teor de água em $40 \mathrm{~mL}$ para todos os ensaios. $\mathrm{O}$ material zeolítico foi obtido através de síntese hidrotérmica, estática e sem envelhecimento, realizada em estufa com circulação de ar através de autoclaves de aço inoxidável revestidas internamente por um vaso de teflon com volume total de 47,4 mL. Após o processo de síntese os produtos formados foram lavados através de filtração com água destilada até $\mathrm{pH} 7-8$, e em seguida submetidos a secagem a $90{ }^{\circ} \mathrm{C}$ por $24 \mathrm{~h}$.

$\mathrm{O}$ material de partida e as fases formadas nos produtos de síntese foram caracterizados por meio de: difração de raios X (DRX) em difratômetro X'Pert Pro MPD (Panalytical) com anodos de $\mathrm{Cu}$, varredura de $5^{\circ}$ a $90^{\circ} \mathrm{em}$ $2 \Theta, 40 \mathrm{kV}$ e $35 \mathrm{~mA}$; microscopia eletrônica de varredura (MEV) com imagens obtidas em microscópio Philips XL30; e espectroscopia de infravermelho (FTIR) em equipamento Thermo-Nicolet Magna $560 \mathrm{com}$ varredura de 400 a $4000 \mathrm{~cm}^{-1}$ e resolução $4 \mathrm{~cm}^{-1}$, aplicando-se a técnica de refletância difusa (DRIFT). 


\section{RESULTADOS E DISCUSSÃO}

A análise mineralógica do rejeito de caulim por difração de raios X (Fig. 1a) indica que este é constituído principalmente do argilomineral caulinita, encontrando-se também quartzo e anatásio como minerais secundários. Pela observação do aspecto da curva de difração da Fig. 1b, notase uma perda de cristalinidade do rejeito, indicando assim, que o processo de metacaulinização a $700{ }^{\circ} \mathrm{C}$ por $2 \mathrm{~h}$ foi eficiente, tornando-se então o material uma fonte propícia para a síntese de zeólitas pois acima da temperatura de desidroxilação a conversão de caulinita em metacaulinita torna a argila mais reativa, variando esta reatividade com o tratamento térmico, o que de certo modo pode afetar no mecanismo e na cinética da reação de zeolitização [24].

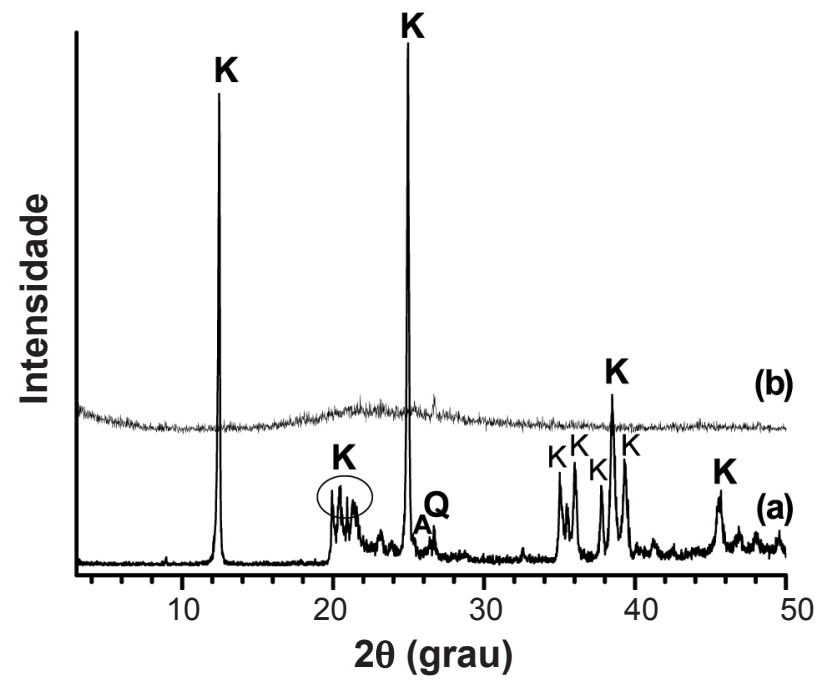

Figura 1: Difratogramas de raios X: (a) rejeito de caulim; (b) rejeito de caulim calcinado. $\mathrm{K}=$ caulinita; $\mathrm{Q}=$ quartzo; $\mathrm{A}=$ anatásio.

[Figure 1: XRD patterns: (a) kaolin waste; (b) calcined kaolin waste. $K=$ kaolinite,$Q=$ quartz; $A=$ anatase.]

\section{Influência da relação $\mathrm{SiO}_{2} / \mathrm{Al}_{2} \mathrm{O}_{3}$ na cristalização}

O metacaulim então produzido foi utilizado nas reações de zeolitização, onde primeiramente, procurou-se investigar a influência da relação entre sílica e alumina na formação dos materiais zeolíticos; pois, este é um dos principais parâmetros que caracterizam e direcionam a formação da estrutura cristalina de uma zeólita [11]. Os ensaios foram realizados a $90{ }^{\circ} \mathrm{C}$ por $20 \mathrm{~h}$, com as amostras obedecendo à seguinte composição: $4 \mathrm{Na}_{2} \mathrm{O}-\mathrm{Al}_{2} \mathrm{O}_{3}-y \mathrm{SiO}_{2}-\mathrm{H}_{2} \mathrm{O}$.

Nos difratogramas da Fig. 2, para razões molares de $\mathrm{SiO}_{2} / \mathrm{Al}_{2} \mathrm{O}_{3}$ mais baixas, obteve-se como fase predominante produtos cristalizados com estrutura do tipo faujasita apresentando no padrão difratométrico reflexões intensas em $2 \theta=6,2^{\circ}(14,16 \AA), 15,6^{\circ}(5,69 \AA), 23,5^{\circ}$ (3,79 $\AA$ ), $26,8^{\circ}$ $(3,32 \AA)$ e $31,1^{\circ}(2,87 \AA)$, mostrando semelhança àquelas encontradas para zeólita NaY [10]. Para relações molares mais altas (5 e 6), zeólita do tipo chabazita foi tida como fase concorrente. Analisando a forma das curvas, pode-se observar que nos produtos obtidos tem-se fases zeolíticas com baixa cristalinidade e a presença de bastante material não cristalino, sendo este, muito provavelmente metacaulinita que, durante a etapa de síntese, não sofreu ataque alcalino o suficiente para sua transformação [24].

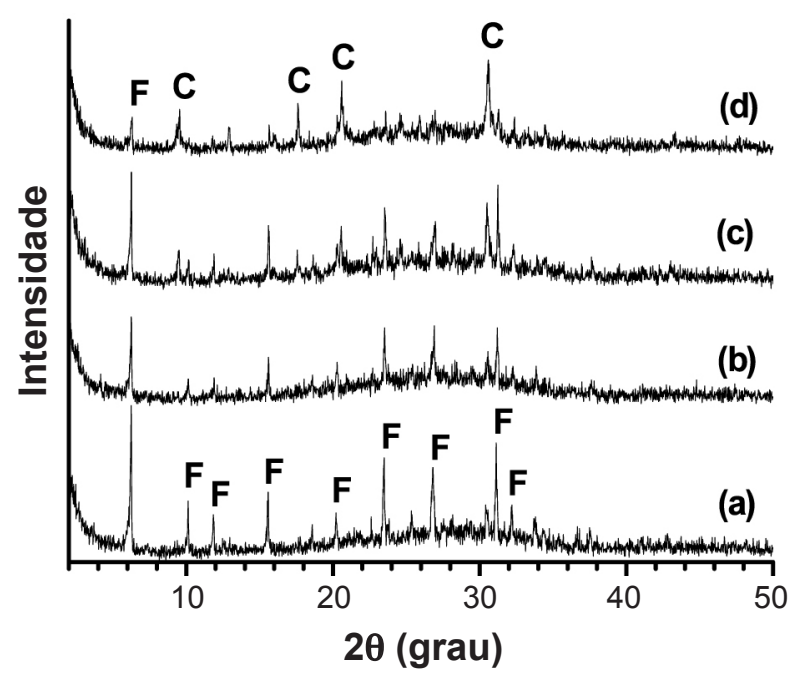

Figura 2: Difratogramas de raios $\mathrm{X}$ dos produtos obtidos a $90{ }^{\circ} \mathrm{C} / 20$ h para diferentes relações de $\mathrm{SiO}_{2} / \mathrm{Al}_{2} \mathrm{O}_{3}$ : (a) 3,00; (b) 4,00; (c) 5,00; e (d) 6,00 mols. $\mathrm{F}=$ faujasita, $\mathrm{C}=$ chabazita.

[Figure 2: XRD patterns of products obtained at $90{ }^{\circ} \mathrm{C} / 20 \mathrm{~h}$ with different $\mathrm{SiO}_{2} / \mathrm{Al}_{2} \mathrm{O}_{3}$ ratios: (a) 3.00; (b) 4.00; (c) 5.00; and (d) 6.00 moles. $F$ = faujasite, $C=$ chabazite. $]$

\section{Influência da temperatura de cristalização}

Com o propósito de se verificar o efeito da temperatura no processo de cristalização do material zeolítico obtido na etapa anterior, foram sintetizadas amostras na relação molar $4 \mathrm{Na}_{2} \mathrm{O}-\mathrm{Al}_{2} \mathrm{O}_{3}-3 \mathrm{SiO}_{2}-\mathrm{H}_{2} \mathrm{O}$. A Fig. 3 revela pelos difratogramas de raios $\mathrm{X}$ que mantendo-se inalteradas as demais condições, ao aumentar a temperatura de síntese, induz a formação de outras fases zeolíticas, estando a zeólitas $\mathrm{NaA}$ entre as fases concorrentes com a zeólita faujasita, verificando-se em ambas, pela intensidade dos picos, um certo aumento na cristalinidade.

\section{Influência do teor de sódio na cristalização}

A alcalinidade é um dos parâmetros mais importantes para o controle da cristalização de zeólitas, e é também responsável pelo tipo de zeólita formada [27]. Com as variáveis tempo e temperatura fixas, foi avaliado o comportamento do teor de sódio na evolução da cristalização de materiais zeolíticos do tipo faujasita. A mistura reacional configurou a seguinte relação: $x \mathrm{Na}_{2} \mathrm{O}-\mathrm{Al}_{2} \mathrm{O}_{3}-3 \mathrm{SiO}_{2}-\mathrm{H}_{2} \mathrm{O}$ variando-se $x$ de 1 a 10 mol. Os difratogramas de raios $\mathrm{X}$ para amostras selecionadas são apresentados na Fig. 4. Conforme observado, a influência do teor de sódio no processo de síntese pode ser dividida em três estágios: no primeiro deles, para concentrações de sódio abaixo de quatro não se tem 
fases zeolíticas cristalizadas, neste aparece apenas uma banda larga característica de material amorfizado. Para um segundo estágio, teor de sódio entre 4 e 7 , tem o surgimento da fase faujasita e concorrendo com esta a zeólita $\mathrm{NaA}$; nesta etapa observa-se um aumento na cristalinidade das zeólitas formadas. À medida que a quantidade de sódio vai aumentando, relação de $\mathrm{Na}_{2} \mathrm{O} / \mathrm{Al}_{2} \mathrm{O}_{3}$ entre 8 e 10 , tem-se a tendência ao desaparecimento das fases, faujasita e $\mathrm{NaA}$;

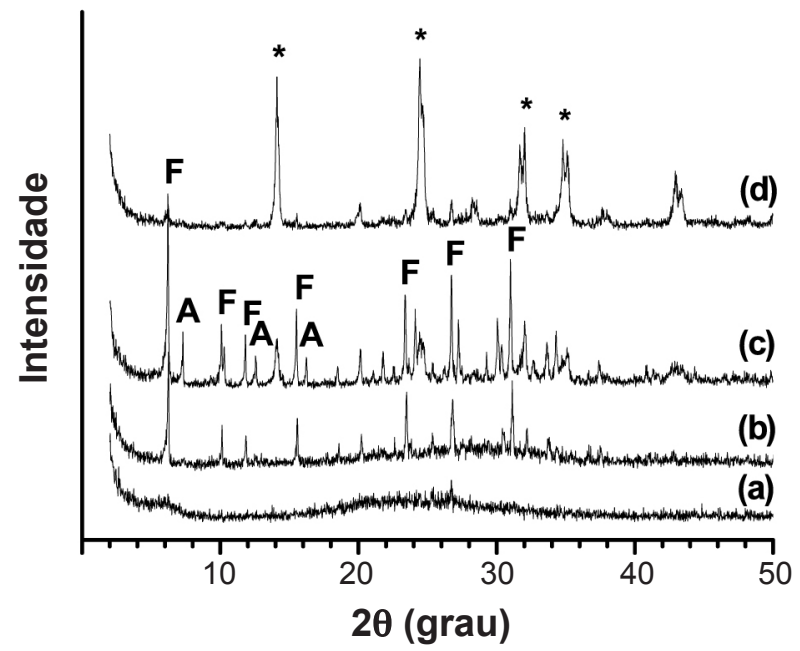

Figura 4: Difratogramas de raios $\mathrm{X}$ dos produtos obtidos a $90{ }^{\circ} \mathrm{C} / 20$ h para diferentes relações de $\mathrm{Na}_{2} \mathrm{O} / \mathrm{Al}_{2} \mathrm{O}_{3}$ : (a) 1,00 ; (b) 4,00; (c) 7,00; e (d) 10,00 mols. F = faujasita; A = zeólita NaA; $*$ = hidroxisodalita.

[Figure 4: XRD patterns of products obtained at $90{ }^{\circ} \mathrm{C} / 20 \mathrm{~h}$ using different $\mathrm{Na}_{2} \mathrm{O}_{\mathrm{Al}} \mathrm{O}_{2} \mathrm{O}_{3}$ ratios: (a) 1.00; (b) 4.00; (c) 7.00; and (d) 10.00 moles. $F=$ faujasite,$A=$ zeolite $N a A, *=$ Hydroxysodalite. $]$

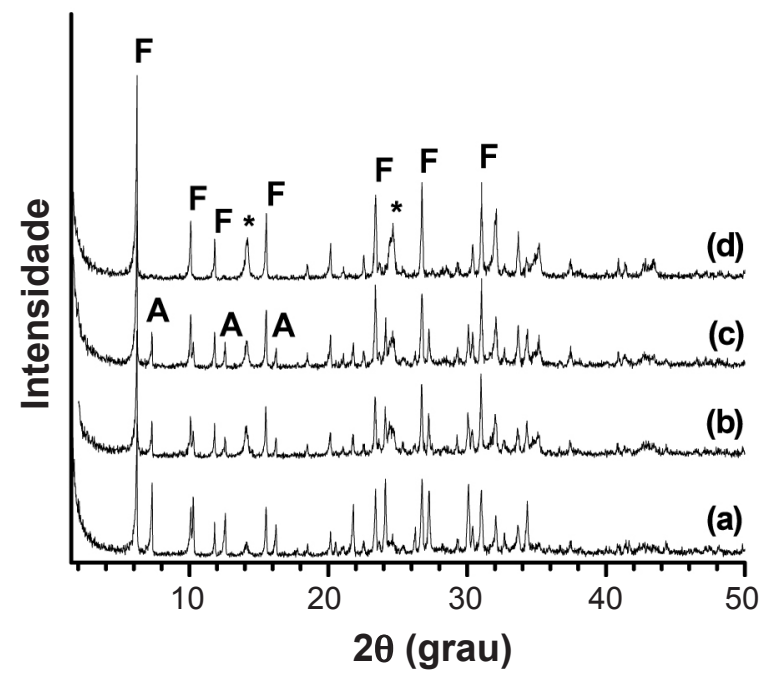

Figura 5: Difratogramas de raios $\mathrm{X}$ dos produtos obtidos a $90{ }^{\circ} \mathrm{C} / 20$ h utilizando a composição molar de $7 \mathrm{Na}_{2} \mathrm{O}-\mathrm{Al}_{2} \mathrm{O}_{3}-3 \mathrm{SiO}_{2}-\mathrm{H}_{2} \mathrm{O}$ para diferentes tempos de síntese: (a) 16; (b) 20; (c) 24; e (d) $48 \mathrm{~h}$. $\mathrm{F}=$ faujasita; $\mathrm{A}=$ zeólita $\mathrm{NaA} ; *$ = Hidroxisodalita.

[Figure 5: XRD patterns of products obtained at $90{ }^{\circ} \mathrm{C} / 20 \mathrm{~h}$ using a molar composition of $7 \mathrm{Na}_{2} \mathrm{O}-\mathrm{Al}_{2} \mathrm{O}_{3}-3 \mathrm{SiO}_{2}-\mathrm{H}_{2} \mathrm{O}$ with different synthesis times: (a) 16; (b) 20;(c)24; and (d) $48 \mathrm{~h}$. F = faujasite, $A$ = zeolite NaA, * = Hydroxysodalite.]
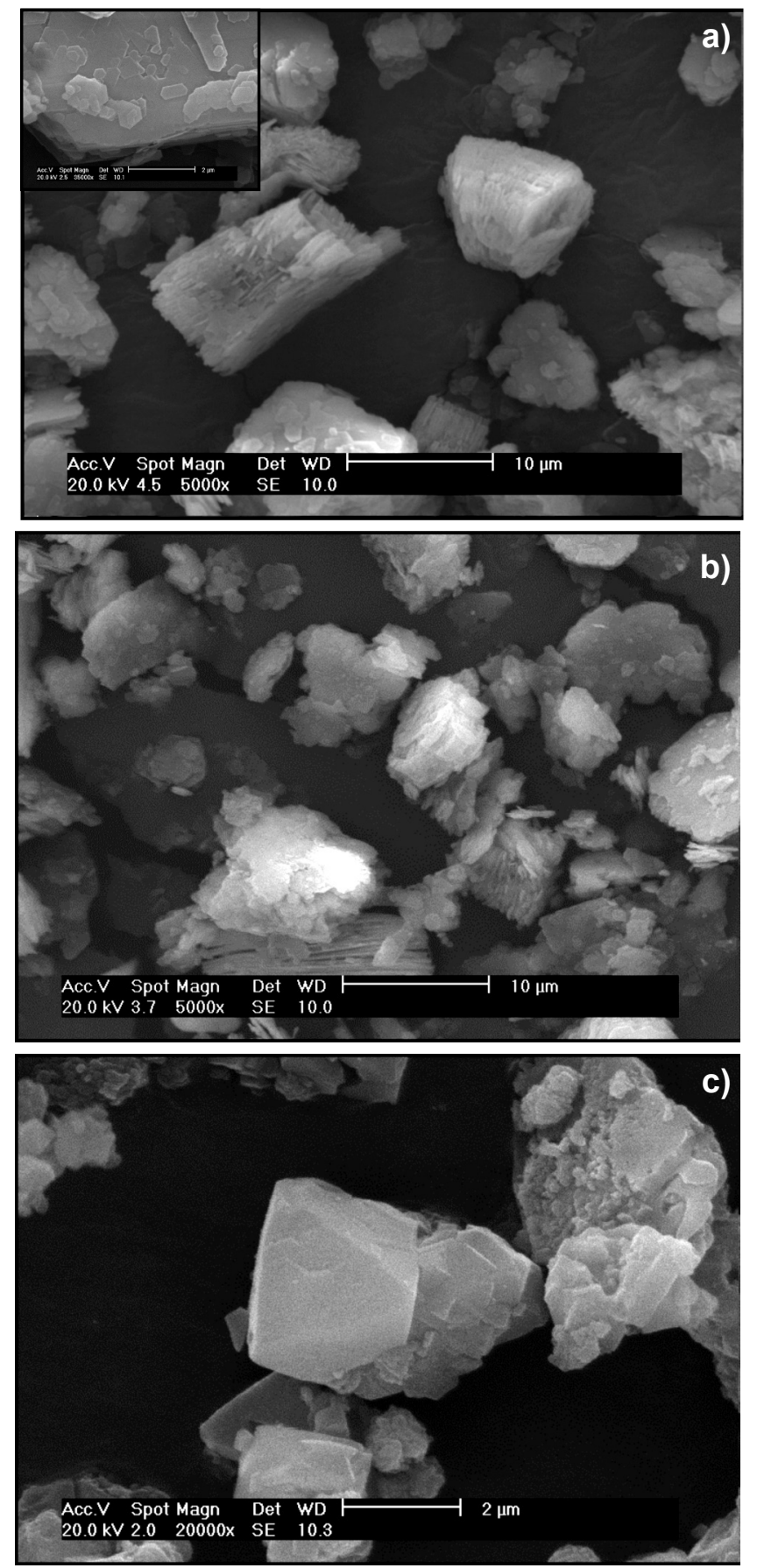

Figura 6: Imagens de MEV: (a) rejeito de caulim; (b) rejeito de caulim calcinado; (c) produto obtido a $90{ }^{\circ} \mathrm{C} / 48 \mathrm{~h}$ com a seguinte composição molar $7 \mathrm{Na}_{2} \mathrm{O}-\mathrm{Al}_{2} \mathrm{O}_{3}-3 \mathrm{SiO}_{2}-\mathrm{H}_{2} \mathrm{O}$.

[Figure 6: SEM images: (a) kaolin waste; (b) calcined kaolin waste; (c) product obtained at $90{ }^{\circ} \mathrm{C} / 48 \mathrm{~h}$ using a molar composition of $7 \mathrm{Na}_{2} \mathrm{O}-\mathrm{Al}_{2} \mathrm{O}_{3}-3 \mathrm{SiO}_{2}-\mathrm{H}_{2} \mathrm{O}$.]

para então surgir, a hidroxisodalita como fase predominante no material sintetizado.

\section{Influência do tempo de cristalização}

Com o objetivo de observar como o tempo de reação influencia no processo de formação da zeólita do tipo 
faujasita, foram sintetizadas amostras de composição molar $7 \mathrm{Na}_{2} \mathrm{O}-\mathrm{Al}_{2} \mathrm{O}_{3}-3 \mathrm{SiO}_{2}-\mathrm{H}_{2} \mathrm{O}$, mantendo-se a temperatura em $90{ }^{\circ} \mathrm{C}$. Verifica-se na Fig. 5 que ao diminuir o tempo da reação para $16 \mathrm{~h}$, nenhuma fase zeolítica diferente é formada. No entanto, ao aumentar o tempo para $48 \mathrm{~h}$, a fase referente à zeólita NaA desaparece, predominando então a fase característica de zeólita do tipo FAU com picos bastante acentuados caracterizando desta forma indícios de boa cristalinidade.

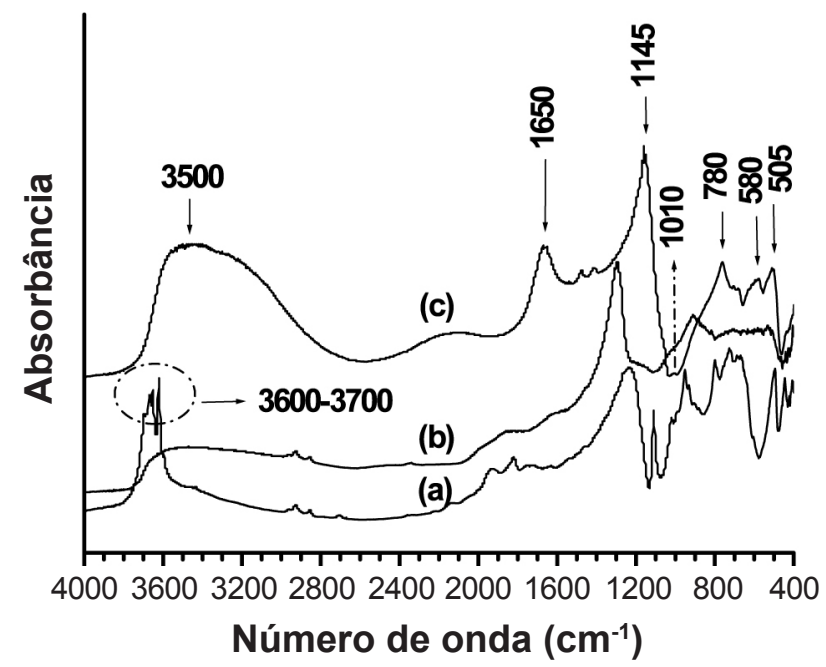

Figura 7: Espectros de DRIFT: (a) rejeito de caulim; (b) rejeito de caulim calcinado; (c) produto obtido a $90{ }^{\circ} \mathrm{C} / 48 \mathrm{~h}$ com a seguinte composição molar $7 \mathrm{Na}_{2} \mathrm{O}-\mathrm{Al}_{2} \mathrm{O}_{3}-3 \mathrm{SiO}_{2}-\mathrm{H}_{2} \mathrm{O}$.

[Figure 7: DRIFT spectra: (a) kaolin waste; (b) calcined kaolin waste; (c) product obtained at $90^{\circ} \mathrm{C} / 48 \mathrm{~h}$ using a molar composition of $7 \mathrm{Na}_{2} \mathrm{O}-\mathrm{Al}_{2} \mathrm{O}_{3}-3 \mathrm{SiO}_{2}-\mathrm{H}_{2} \mathrm{O}$.]

É possível acompanhar o progresso das reações de síntese por meio da mudança morfológica visualizadas nos produtos obtidos através das imagens de MEV da Fig. 6. Verifica-se que o rejeito é constituído predominantemente por partículas aglomeradas (empilhamento tipo booklets), com cristais peseudo-hexagonais (Fig. 6a, imagem menor), que são característicos da caulinita; enquanto que no rejeito calcinado, Fig. 6b, o empilhamento é alterado mantendo-se, porém a forma $[8,28]$. A morfologia da amostra sintetizada (Fig. 6c) se apresenta similar àquela reportada [14, 29], no qual a zeólita do tipo faujasita é identificada por formas octaédricas (bipiramidal); nota-se na micrografia que o cristal apresenta-se bem definido, indicando assim boa cristalinidade para a fase sintetizada. Cristais com outras formas (cúbicos, esféricos, etc.) não foram encontrados, demonstrando assim, a predominância da fase zeolítica do tipo FAU nas amostras analisadas.

Através da observação dos espectros vibracionais da Fig. 7 pode-se acompanhar as transformações que ocorrem desde o material de partida até os produtos de síntese. Verificase para o rejeito de caulim (Fig. 5a) bandas de estiramento do grupo $\mathrm{OH}$ em 3697,3653 e $3621 \mathrm{~cm}^{-1}$, característico de caulinita [30]; a ausência destas bandas de vibrações no espectro do rejeito de caulim calcinado (Fig. 5b) está relacionada à conversão da caulinita em metacaulinita em virtude da perda dos grupos $\mathrm{OH}$ da rede cristalina [28, 31]. Para as amostras sintetizadas, as bandas com um máximo a 3500 e $1650 \mathrm{~cm}^{-1}$ são peculiares de vibrações de grupos funcionais do tipo $\mathrm{OH}$ e são atribuídas a águas de natureza zeolíticas, comportamento semelhante ao encontrado na obtenção de zeólita A [9]; freqüências observadas em torno de $1145,1010,780,580$ e $505 \mathrm{~cm}^{-1}$ sugerem que na amostra produzida (Fig. 3c) existe material zeolítico com estrutura tipo FAU, pois estas encontram características semelhantes àquelas relatadas para zeólita $\mathrm{NaY}[21,29]$.

\section{CONCLUSÕES}

Zeólita do tipo faujasita foi sintetizada após o rejeito de caulim ter sido termicamente ativado e em seguida utilizado como fonte predominante de silício e de alumínio. As condições para obtenção de faujasita com boa cristalinidade foram conseguidas na composição molar $7 \mathrm{Na}_{2} \mathrm{O}-\mathrm{Al}_{2} \mathrm{O}_{3}$ - $3 \mathrm{SiO}_{2}-\mathrm{H}_{2} \mathrm{O}$, com as reações de zeolitização ocorrendo a $90{ }^{\circ} \mathrm{C}$ por $48 \mathrm{~h}$, não sendo necessário submeter o gel a envelhecimento. Zeólita $\mathrm{NaA}$ e hidroxisodalita também foram obtidas em condições diferenciadas de síntese, existindo assim uma aparente competição entre estas fases e zeólita do tipo faujasita. Deste modo, é importante um controle rigoroso dos parâmetros de reação para se obter a fase zeolítica desejada.

\section{AGRADECIMENTOS}

À CAPES e à Companhia Vale S/A pelo apoio a esta pesquisa.

\section{REFERÊNCIAS}

[1] H. H. Murray, Appl. Clay Sci. 17 (2000) 207-221.

[2] M. L. Costa, D. J. L. Sousa, R. S. Angélica, J. South Am. Earth Sci. 27 (2009) 219-234.

[3] A. C. Silva, M. Vidal, M. G. Pereira, Rev. Esc. Minas 54, 2 (2001) 133-136.

[4] R. R. Menezes, M. F. Oliveira, L. N. L. Santana, G. A. Neves, H. C. Ferreira, Cerâmica 53, 328 (2007) 388-395.

[5] S. M. P. Flores, R. F. Neves, Cerâmica 43, 283-284 (1997) 175-179.

[6] M. S. Barata, D. C. C. Dal Molin, Ambient. Constr. 2, 1 (2002) 69-78.

[7] A. A. B. Maia, R. S. Angélica, R. F. Neves, Cerâmica 54, 331 (2008) 345-350.

[8] S. P. A. Paz, R. S. Angélica, R. F. Neves, Quím. Nova, 33, 3 (2010) 579-583.

[9] A. A. B. Maia, R. S. Angélica, R. F. Neves, Clay Miner. 46, (2011)127-136.

[10] D. W. Breck, Zeolite molecular sieves: structure, chemistry, and use, John Wiley \& Sons, New York, EUA (1974).

[11] A. Dyer, An Introduction to Zeolite Molecular Sieves, John Wiley \& Sons, New York, EUA (1988). 
[12] G. Gianetto, A. Montes, G. Rodríguez, Zeolitas: Características, propriedades y aplicaciones industriales, $2^{\mathrm{a}}$ Ed., Editorial Innovación Tecnológica, Caracas, Venezuela (2000).

[13] A. Y. Atta, O. A. Ajayi, S. S. Adefila, J. Appl. Sci. Res. 3, 10 (2007) 1017-1021.

[14] A. S. Kovo, O. Hernandez, S. M. Holmes, J. Mater. Chem. 19 (2009) 6207-6212.

[15] C. A. Ríos, C. D. Williams, M. A. Fullen, Appl. Clay Sci. 42 (2009) 446-454.

[16] C. R. Melo, H. G. Riella, Cerâmica 56, 340 (2010) 340346.

[17] M. L. Mignoni, D. I. Petkowicz, N. R. C. F. Machado, S. B. C. Pergher, Appl. Clay Sci. 41 (2008) 99-104.

[18] S. Chandrasekhar, P. N. Pramada, J. Porous Mater. 6 (1999) 283-297.

[19] F. G. Colina, J. Llorens, Micropor. Mesopor. Mater. 100 (2007) 302-311.

[20] X. Liu, Z. Yan, H. Wang, Y. Luo, J. Nat. Gas Chem. 12, 1 (2003) 63-70.

[21] L. Qiang, Z. Ying, C. Zhijun, G. Wei, C. Lishan, Petr. Sci. 7 (2010) 403-409.
[22] J. F. Lambert, W. S. Millman, J. J. Fripiat, J. Am. Ceram. Soc. 111 (1989) 3517-3522.

[23] D. Massiot, P. Dion, J. F. Alcover, F. Bergaya, J. Am. Ceram. Soc. 78 (1995) 2940-2944.

[24] L. Heller-Kallai, I. Lapide, Appl. Clay Sci. 35 (2007) 99-107.

[25] J. Cejka, H. V. Bekkum, A. Corma, F. Schuth, Introduction to Zeolite Science and Practice, $3^{\text {rd }}$ Ed., Elsevier, Amsterdam, Holanda (2007).

[26] W. Vermeiren, J. P. Gilson, Top. Catal. 52 (2009) 1131 1161.

[27] H. Lechert, Micropor. Mesopor. Mater. 22 (1998) 519523.

[28] P. Souza Santos, Ciência e Tecnologia de Argilas, $2^{\mathrm{a}}$ Ed., Vol. 2, Edgard Blucher, S. Paulo, Brasil (1992).

[29] C. Covarrubiasa, R. García, R. Arriagada, J. Yánez, M. T. Garland, Micropor. Mesopor. Mater. 88 (2006) 220-231. [30] B. S. Carneiro, R. S. Angélica, T. Scheller, E. A. S. Castro, R. F. Neves, Cerâmica 49, 312 (2003) 237-244.

[31] J. Cuadros, T. Dudek, Clays Clay Miner. 54, 1 (2006) $1-11$.

(Rec.26/08/2011, Rev.21/11/2011, Ac.21/01/2012) 